ORIGINAL ARTICLE

PRACA ORYGINALNA

\title{
EFFECT OF ENDOSTATIN AND INSULIN-LIKE GROWTH FACTOR-1 ON ANGIOGENESIS IN PATIENTS WITH ACUTE MYOCARDIAL INFARCTION WITH OBESITY UNDER THE INFLUENCE OF ZOFENOPRIL
}

D0I: 10.36740/WLek202001111

\author{
Dmytro V. Martovytskyi, Olexiy M. Shelest, Pavlo G. Kravchun \\ KHARKIV NATIONAL MEDICAL UNIVERSITY, KHARKIV, UKRAINE
}

\begin{abstract}
The aim: To study the dynamics of markers of angiogenesis based on insulin-like growth factor-1 (IGF-1) and endostatin, as well as to determine 6-month survival in patients taking zofenopril from the first day of AMI with and without obesity.

Materials and methods: using enzyme immunoassay, we determined the level of endostatin and IGF- 1 in serum on days 1 and 12 in patients with AMI with the presence and absence of obesity, and a statistical processing of the data obtained.

Results: The relationship between obesity and angiogenesis indicators, both activators and inhibitors, was determined, and a significant relationship was found between zofenopril therapy and angiogenesis activator IGF-1. Differences in the survival of patients with complicated AMI were determined depending on the choice of ACE inhibitor in favor of a higher survival rate of patients who took zofenopril.

Conclusions: patients who underwent complicated AMI, taking zofenopril, have a higher survival rate during the 6-month follow-up period. Zofenopril stimulated angiogenesis in the examined patients, which was expressed in patients with and without obesity.
\end{abstract}

KEY WORDS: endostatin, IGF-1, acute myocardial infarction, obesity, zofenopril

Wiad Lek. 2020;73(1):63-67

\section{INTRODUCTION}

Despite all the modern advances in medicine and technology, cardiovascular diseases currently occupy a leading place in the world in mortality [1].

Everyone knows such factors as: hyperlipidemia, dyslipidemia, diabetes, metabolic syndrome, smoking, sedentary lifestyle, hypertension, which play a very important role in the development and progression of atherosclerosis [2]. In recent years, more and more attention has been paid to the issues of endothelial dysfunction and angiogenesis of plaques as factors for the development and progression of coronary heart disease [3].

Today, metabolic syndrome is a serious public health problem. The main danger is associated with an increased risk of cardiovascular diseases, stroke, type 2 diabetes mellitus and a growing risk of mortality. Metabolic syndrome stimulates the occurrence of early atherosclerosis, its progress and accelerates the frequency of cardiovascular complications associated with atherosclerosis and diabetes mellitus [4]. More and more patients with obesity and overweight are registered worldwide. Obesity, as one of the indicators of metabolic syndrome, is a risk factor for the development of many diseases, such as: coronary heart disease, hypertension, diabetes mellitus [5].

In healthy people, the vascular endothelium plays a key role in maintaining homeostasis, since its functions include inhibition of blood coagulation in the vessel lumen, vasodilation of the vascular wall, regulation of the coagulation processes, thrombosis and fibrinolysis, immune and inflammatory reactions, neovasculogenesis and prevention of proliferation of smooth muscles, [6]. However, endothelial function may be impaired, due to which an imbalance of angiogenesis factors occurs, leading to a state in which vasoconstriction, thrombosis, proliferation of vascular smooth muscle cells and the formation of atherosclerotic plaques occur [7].

When establishing endothelial dysfunction, an imbalance between pro- and anti-angiogenic factors contributes to the occurrence of hemorrhagic, immature capillaries inside the vessel wall or inside nascent plaques. Thus, the regulation of angiogenesis appears to be a key factor in the spread of coronary artery disease and atherosclerotic plaque rupture [3].

In this study, angiogenesis factors such as insulin-like growth factor-1 (IGF-1) and endostatin were considered. IGF- 1 is a product of the IGF- 1 gene, which is located on chromosome 12 [8]. On the first and second exons, there are two sites for running transcripts showing the results in two different carboxyl terminal domains for IGF-1 (Ea and $\mathrm{Eb})$. Eb transcripts are mainly expressed in the liver. In addition, IGF-1 is also synthesized in the kidneys, car- 
diomyocytes, smooth muscle vascular cells, fibroblasts, etc. IGF-1 was identified as a valuable indicator of impaired glucose tolerance, and therefore its association with the presence of coronary atherosclerosis was suggested. Several studies have evaluated the relationship between the level of IGF-1 and the severity of atherosclerosis [9]. It has now been established that endothelial dysfunction is an early event in atherogenesis that precedes intimal thickening and the formation of atherosclerotic plaques. A feature of endothelial dysfunction is the reduced bioavailability of the anti-atherosclerotic nitric oxide molecule (NO). In the course of research, there is evidence that IGF-1 is a powerful vasodilator [10]. In endothelial cells, IGF-1, interacting with its receptor, stimulates the formation of $\mathrm{NO}$, contributing to the regulation of vascular tone [11].

Endostatin is a fragment of the C-terminal region of collagen XVIII [12]. Endostatin is found in the walls of blood vessels (elastic fibers) and membranes with a strong effect of modulating angiogenesis and is a component of almost all epithelial and endothelial membranes in the human body [13]. According to known data, endostatin induces apoptosis of endothelial cells [14], plays an important role in the adhesion of endothelial cells [15] and impairs the maturation of blood vessels during wound healing, which leads to a decrease in angiogenesis [16].

Obesity, low physical activity, diabetes mellitus can affect the level of endostatin in serum [17, 18]. Disrupted endostatin levels in the blood serum are associated with cerebrovascular diseases, organ damage in hypertension [19]. Due to the serum level of endostatin, mortality from cardiovascular diseases in people with ischemic heart disease can be predicted [20].

According to international recommendations, angiotensin-converting enzyme (ACE) inhibitors are considered to be one of the most important drugs for treating patients with a high risk of developing cardiovascular diseases, as well as necessary drugs for the prevention of complications after acute myocardial infarction (AMI). Zofenopril is a highly lipophilic ACE inhibitor that is characterized by sustained inhibition of the progression of heart failure. As was shown in preclinical studies, zofenopril has cardioprotective properties and affects left ventricular remodeling in myocardial damage [21]. It is known that therapy with zofenopril may be an important support for ensuring a favorable prognosis for patients with a high risk of cardiovascular diseases after AMI [22].

\section{THE AIM}

Objective: to study the dynamics of angiogenesis inhibitors and activators based on IGF-1 and endostatin, as well as 6-month survival in patients with and without obesity after AMI under the influence of treatment with zofenopril.

\section{MATERIALS AND METHODS}

The study involved 105 patients with AMI and concomitant obesity who were treated in the infarction department of
Kharkiv City Clinical Hospital No. 27 (mean age 64.6 \pm 7.4 years). 55 patients had AMI and concomitant obesity, and 50 patients with AMI without obesity. The studied groups were comparable by sex and age. The control group consisted of 20 healthy individuals of appropriate age and gender.

AMI was diagnosed in accordance with the recommendations (recommendations of the ESC for the treatment of acute myocardial infarction in patients with ST-segment elevation 2017).

The anthropometric indices were determined: height $(\mathrm{cm})$, body weight $(\mathrm{kg})$, body mass index (BMI), which was calculated by the formula: BMI = body weight, $\mathrm{kg}$ / height, $\mathrm{m}^{2}$. Obesity was diagnosed as recommended (American Association of Clinical Endocrinologists and American College of Endocrinological Clinical Practice for Comprehensive Medical Care for Obese Patients, 2016). With a BMI of 18.5 to $24.9 \mathrm{~kg} / \mathrm{m}^{2}$, normal weight, from 25.0 to $29.9 \mathrm{~kg} / \mathrm{m}^{2}$, increased body weight, and from 30 $\mathrm{kg} / \mathrm{m}^{2}$ and more, obesity.

There were 44 patients with complicated AMI: post-infarction angina $(n=15)$, atrial fibrillation $(n=12)$, ventricular fibrillation $(\mathrm{n}=2)$, atrioventricular blockade $(n=4)$, pulmonary edema $(n=4)$, cardiac asthma $(n=2)$, thromboembolism of pulmonary artery $(n=3)$, repeated myocardial infarction $(\mathrm{n}=2)$.

To determine the levels of IGF-1 (MEDIAGNOST, Germany), endostatin (BIOMEDICA, Austria), an enzyme immunoassay was used. Indicators of IGF-1 and endostatin were determined on the first and twelfth days of AMI.

Standard therapy was used for treatment of patients with AMI: percutanieus intervention, thrombolytic therapy, anticoagulants, antiplatelets, $\beta$-blockers, and also ACE inhibitors (zofenopril or enalapril). Zofenopril was used according to the scheme: 1-2 days of AMI, $7.5 \mathrm{mg} 2$ times a day, 3-4 days $15 \mathrm{mg} 2$ times a day, after 5 days $30 \mathrm{mg} 2$ times a day. Enalapril was used according to the scheme $10 \mathrm{mg} 2$ times a day.

Statistical processing was carried out using the program STATISTICA 10.0. Data are given as $M \pm m$, where $M$ is the mean and $m$ is the standard error of the mean. The risk ratio (HR) and 95\% confidence intervals (CI) were calculated using the Cox proportional risk regression model. Considering the different periods of observation for the patients examined, the relative risk of mortality from cardiovascular diseases was assessed using a time-dependent regression model and corresponding survival curves. Statistically significant differences were considered at $\mathrm{p}<0.05$.

\section{RESULTS AND DISCUSSION}

As a result of a 6-month follow-up in a group of patients with complicated AMI who received the recommended therapy with zofenopril, compared with another, similar in all parameters, group of patients who received therapy with enalapril, the $\mathrm{HR}$ risk ratio was 0.81 (0.61-0.95, $\mathrm{P}=$ $0.041)$. As can be seen, comparing the data of Figure 1 and Figure 2, the 6-month survival in patients with complicated AMI who received zofenopril was significantly higher than 

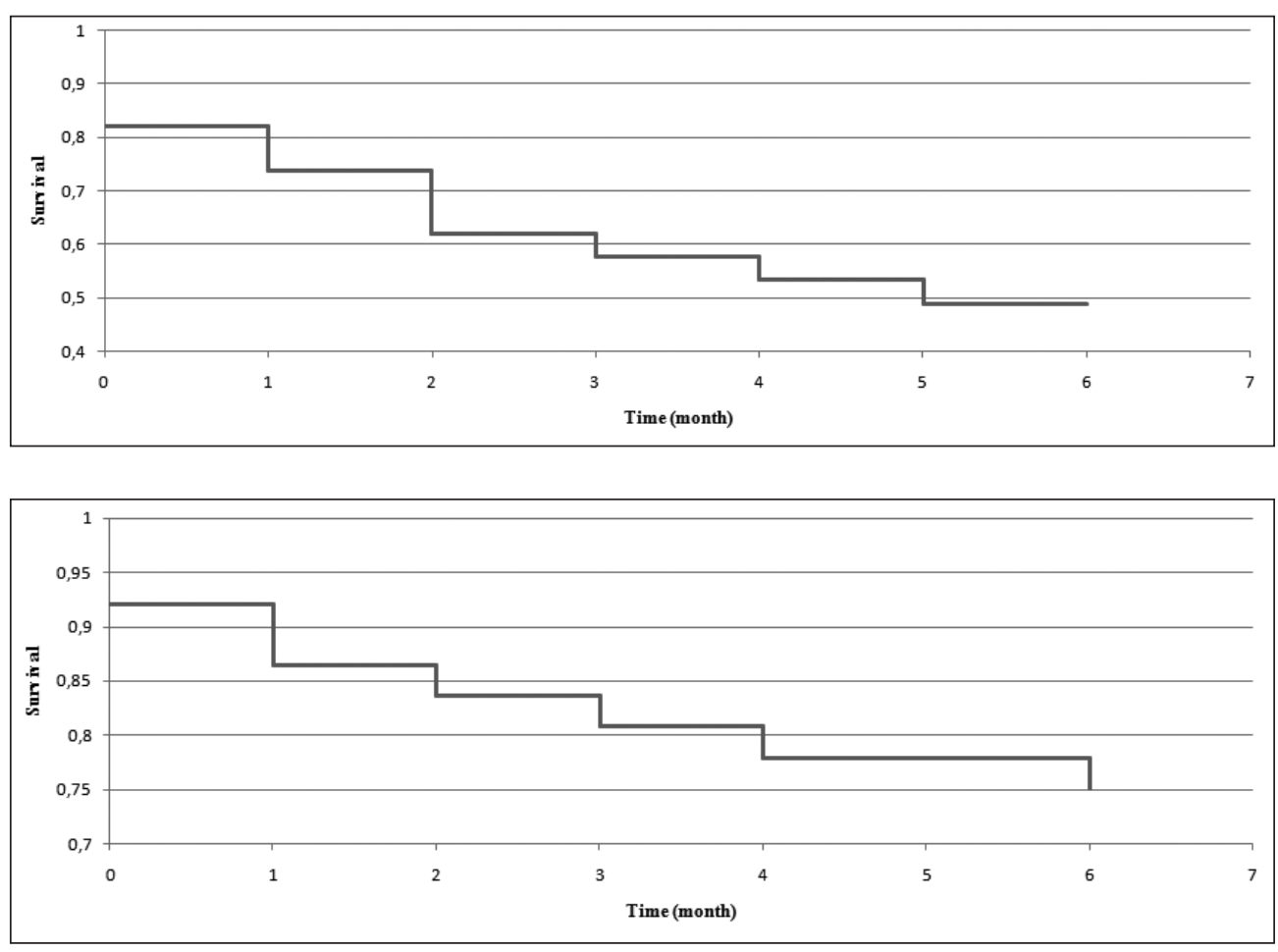

Fig. 1. Survival in patients with complicated AMI without obesity who received therapy with enalapril
Fig. 2. Survival in patients with complicated AMI without obesity who received therapy with zofenopril.

Table I. Dynamics of indicators of angiogenesis in patients with complicated acute myocardial infarction in patients without obesity

\begin{tabular}{ccccc}
\hline Drug & Endostatin in $\mathbf{1}$ day, pmol/I & Endostatin in 12 day, pmol/I & IGF-1 in 1 day, ng/mI & IGF-1 in 12 day, ng/ml \\
\hline Zofenopril & $152,49 \pm 5,75$ & $131,19 \pm 5,31^{*}$ & $135,07 \pm 8,04$ & $159,07 \pm 8,57^{*}$ \\
\hline Enalapril & $157,11 \pm 6,53$ & $160,91 \pm 5,84$ & $139,19 \pm 7,88$ & $119,66 \pm 5,92^{*}$ \\
\hline
\end{tabular}

*- $p<0,05$, as compared with 1 day of AMI.

Table II. Dynamics of indicators of angiogenesis in patients with complicated acute myocardial infarction in patients with obesity

\begin{tabular}{ccccc}
\hline Drug & Endostatin in $\mathbf{1}$ day, pmol/I & Endostatin in $\mathbf{1 2}$ day, pmol/I & IGF-1 in $\mathbf{1}$ day, $\mathbf{~ g / m l ~}$ & IGF-1 in $\mathbf{1 2}$ day, ng/ml \\
\hline Zofenopril & $142,78 \pm 5,12$ & $138,37 \pm 5,66$ & $174,07 \pm 11,15$ & $202,07 \pm 12,22^{*}$ \\
\hline Enalapril & $149,11 \pm 5,84$ & $144,11 \pm 5,68$ & $171,81 \pm 10,48$ & $182,66 \pm 7,32$ \\
\hline
\end{tabular}

* $p<0,05$, as compared with 1 day of AMI.

in the group of patients who received enalapril. These figures show that the greatest number of deaths when using zofenopril occurred in the first month of AMI $(30.77 \%$ of the total), and in the treatment with enalapril - in the second month after the coronary event (28.12\% of the total). In the future, mortality rates decreased to a minimum in the last 6th month of observation.

A dynamic change in the indices of the activator and angiogenesis inhibitor in patients with complicated AMI under the influence of zofenopril and enalapril therapy depending on the presence of obesity was also determined.

From Table I it is seen that in patients with complicated AMI without obesity who received therapy with zofenopril, there was a statistically significant decrease in the level of endostatin $(152.49 \pm 5.75 \mathrm{pmol} / \mathrm{l}$ and $136.19 \pm 5.31 \mathrm{pmol}$ / 1 , respectively, $\mathrm{p}<0.05)$, as well as an increase in the level of IGF-1 (135.07 $\pm 8.04 \mathrm{ng} / \mathrm{ml}$ and $169.07 \pm 8.57 \mathrm{ng} / \mathrm{ml}$, respectively, $\mathrm{p}<0.05)$. The dynamics of endostatin in patients who received enalapril therapy was not statistically significant, however, there was a decrease in the level of
IGF-1 $(139.19 \pm 7.88 \mathrm{ng} / \mathrm{ml}$ and $119.66 \pm 3.92 \mathrm{ng} / \mathrm{ml}$, respectively, $\mathrm{p}<0.05)$.

In Table II, the data of patients with complicated AMI and concomitant obesity are presented, there is a statistically significant increase in the level of IGF-1 in patients who received zofenopril $(174.07 \pm 11.15 \mathrm{ng} / \mathrm{ml}$ and $202.07 \pm 12.22 \mathrm{ng} / \mathrm{ml}$, respectively, $\mathrm{p}<0.05)$. There is also a significant difference between the indices of IGF-1 level in patients with obesity and without obesity at all stages of observation (135.07 $\pm 8.04 \mathrm{ng}$ $/ \mathrm{ml}$ and $174.07 \pm 11.15$ on the first day of acute MI, as well as $159,07 \pm 8,57 \mathrm{ng} / \mathrm{ml}$ and 202,07 $\pm 12,22 \mathrm{ng} / \mathrm{ml}$ for 12 days of acute $\mathrm{MI}$, respectively, $\mathrm{p}<0.05$ ), compared to patients receiving therapy with zofenopril. The difference of the other indicators was not statistically significant.

In Ukraine, as well as throughout the world, cardiovascular diseases are the most common pathology and the leading cause of death among patients [1]. The combination of pathology of the cardiovascular system and obesity further aggravates the patient's condition and increases the risk of complications and mortality in such patients [23]. 
Studies of markers of angiogenesis in patients with AMI and the data obtained give us a reason to talk about their effect on the progression of cardiovascular diseases. The diagnostic role of endostatin and IGF-1 in AMI is beyond doubt $[24,25]$.

Scientists have conducted studies where it was reported that the level of IGF-1 may increase with obesity $[26,27]$. Other studies [28] show that the level of IGF-1 does not increase or may even be decreased [29]. In our study, it is clearly seen that the level of IGF-1 in patients with AMI and obesity was increased in comparison with a comparable group of patients without obesity.

Many scientists have noted the beneficial effect of ACE inhibitors for the further survival of patients with AMI $[30,31]$. We studied the member of this group of drugs - zofenopril. The beneficial effect of zofenopril on angiogenesis was revealed: an increase in the level of IGF-1 in all categories of patients, as well as a decrease in endostatin in patients without obesity. Occurrence a higher survival rate was also registered in patients who took zofenopril since the AMI, which is consistent with the results of other studies [22, 32].

\section{CONCLUSIONS}

1. The level of IGF-1 in patients with AMI and obesity is significantly higher than the level of IGF-1 in patients with AMI without obesity.

2. Treatment with zofenopril compared to the use of enalapril has a positive effect on the activation of angiogenesis in the form of an increase in the level of IGF-1 in all categories of patients.

3. In patients who were under the treatment of zofenopril from the first day of AMI, there are higher rates of survival in the 6-month follow-up period.

\section{REFERENCES}

1. World Health Organization . Health statistics and information systems. Geneva: Global Health Estimates World Health Organization; 2015.

2. Petrie JR., Tomasz J. Guzik TJ, Touyz RM. Diabetes, Hypertension, and Cardiovascular Disease: Clinical Insights and Vascular Mechanisms. Can J Cardiol. 2018;34(5):575-584. doi: 10.1016/j.cjca.2017.12.005.

3. Michel JB, Martin-Ventura JL, Nicoletti A, Ho-Tin-Noe B. Pathology of human plaque vulnerability: mechanisms and consequences of intraplaque haemorrhages. Atherosclerosis. 2014;234(2):311-9. doi:10.1016/j.atherosclerosis.2014.03.020.

4. Kazlauskienè L, Butnorienè J, Norkus A.. Metabolic syndrome related to cardiovascular events in a 10-year prospective study. Diabetol Metab Syndr. 2015. V7:102. https://doi.org/10.1186/s13098-015-0096-2

5. Kunwar R, Minhas S, Mangla V. Is obesity a problem among school children? Indian J Public Health. 2018;62(2):153-155. doi: 10.4103/ ijph.IJPH_430_16.

6. Polonetsky 0.L., Polonetsky L.Z. Disfunktsiya endoteliya I ateroscleroz [Endothelial dysfunction and atherosclerosis]. Medical news. 2012; 6:6-11 (In Belorussia).

7. Hebert C, Siavash H, Norris K et al. Endostatin inhibits nitric oxide and diminishes VEGF and collagen XVIII in squamous carcinoma cells. Int J Cancer. 2005; 114(2):195-201. doi:10.1002/ij.20692.
8. Delafontaine P, Song Y-H, Li Y. Expression, regulation, and function of IGF-1, IGF-1R, and IGF-1 binding proteins in blood vessels. Arterioscler Thromb Vasc Biol. 2004;24:435-444. doi: 10.1161/01. ATV.0000105902.89459.09.

9. Yousefzadeh G, Masoomi M, Emadzadeh A et al. The association of insulin-like growth factor-1 with severity of coronary artery disease. J Cardiovasc Med. 2013; 14(6):416-420.

10. Perticone F, Ceravolo R, Pujia A et al. Prognostic significance of endothelium dysfunction in hypertensive patients. Circulation. 200;04:191-196.

11. Chisalita SI, Arnqvist HJ. Insulin-like growth factor 1 receptors are more abundant than insulin receptors in human micro- and macrovascular endothelial cells. Am J Physiol Endocrinol Metab. 2004;286:896-901.

12. Sasaki T, Larsson H, Tisi D et al. Endostatins derived from collagens XV and XVIII differ in structural and binding properties, tissue distribution, and antiangiogenic activity. J Mol Biol. 2000;301:1179-1190.

13. Zatterstrom UK, Felbor U, Fukai N, Olsen BR. Collagen XVIII/ endostatin structure and functional role in angiogenesis. Cell Struct Funct. 2000;25:97-101.

14. O'Reilly MS, Boehm T, Shing Y et al. Endostatin: An endogenous inhibitor of angiogenesis and tumor growth. Cell. 1997;88:277-285.

15. Dixelius J, Cross M, Matsumoto T et al. Endostatin regulates endothelial cell adhesion and cytoskeletal organization. Cancer Res. 2002;62:1944-1947.

16. Bloch W, Huggel $K$, Sasaki T et al. The angiogenesis inhibitor endostatin impairs blood vessel maturation during wound healing. FACEB J. 2000;14:2373-2376.

17. Sponder M, Dangl D, KampfS et al. Exercise increases serum endostatin levels in female and male patients with diabetes and controls. Cardiovasc Diabetol. 2014;13:6.

18. Sponder M, Sepiol K, Lankisch S et al. Endostatin and physical exercise in young female and male athletes and controls. Int J Sports Med. 2014;35:1138-1142. doi: 10.1055/s-0034-1375692.

19. Carlsson AC, Ruge T, Sundström J et al. Association between circulating endostatin, hypertension duration, and hypertensive target-organ damage novelty and significance. Hypertension. 2013;62:1146-1151. doi: 10.1161/HYPERTENSIONAHA. 113.02250

20. Ärnlöv J, Ruge T, Sundström J et al. Serum endostatin and risk of mortality in the elderly significance. Arterioscler Thromb Vasc Biol. 2013;33 (11):2689-2695. doi: 10.1161/ATVBAHA.113.301704.

21. Ambrosioni E. "Defining the role of zofenopril in the management of hypertension and ischemic heart disorders". Am J Cardiovasc Drug. 2007;7(1):17-24. doi:10.2165/00129784-200707010-00002. PMID17355163.

22. Borghi C, Omboni S, Reggiardo $G$ et al. Efficacy of zofenopril compared with placebo and other angiotensin-converting enzyme inhibitors in patients with acute myocardial infarction and previous cardiovascular risk factors: a pooled individual data analysis of 4 randomized, double-blind, controlled, prospective studies. J Cardiovasc Pharmacol. 2017;69(1):48-54. doi: 10.1097/FJC.0000000000000440.

23. McPherson R. Obesity and Ischemic Heart Disease. Circ Res. 2015;116(4):570-571.

24. Yusuke $H$, Henry $C Q$, Summit $T$ et al. The interaction between IGF-1, atherosclerosis and vascular aging. Front Horm Res. 2014;43:107-124. doi: 10.1159/000360571.

25. Chenglong Zheng, Panchu Yang, Lu Zhang et al. Angiogenesis and expression of vascular endothelial growth factor and endostatin protein in myocardial infarction rat model. Bangl J Pharmacol. 2016;11:1-7. doi: http://dx.doi.org/10.3329/bjp.v11i0.26416. 
26. Frystyk J, Vestbo E, Skjaerbaek C et al. Free insulin-like growth factors in human obesity. Metabolism. 1995; 10:37-44. doi: 10.1016/00260495(95)90219-8.

27. Liwitt MS, Dent MS, Hall K. The Free insulin-like growth factors system in obesity, insulin resistance and type 2 diabetes mellitus. J Clin Med. 2014; 3(4): 1561-1574. doi: 10.3390/jcm3041561/

28. Ricart W, Fernandez-Real JM No decrease in free IGF-I with increasing insulin in obesity-related insulin resistance. Obes Res. 2001; 9:631-636. doi: 10.1038/0by.2001.83.

29. Gomez JM., Maravall FJ, Gomez N et al. The IGF-I system component concentrations that decrease with ageing are lower in obesity in relationship to body mass index and body fat. Growth Horm IGF Res. 2004; 14:91-96. doi:10.1016/j.ghir.2003.11.004.

30. Amsterdam $E$, Wernger $N$, Brindis R et al. AHA/ACC guideline for the management of patients with non-ST-elevation acute coronary syndromes: executive summary: a report of the American College of Cardiology/American Heart Association Task Force on Practice Guidelines. Circulation. 2014; 130:2354.

31. Evans M, Carrero JJ, Szummer K et al. Angiotensin-converting enzyme inhibitors and angiotensin receptor blockers in myocardial infarction patients with renal dysfunction. J Am Coll Cardiol. 2016; 67:1687.

32. Borghi C, Omboni $S$, Reggiardo $G$ et al. Efficacy of zofenopril in combination with amlodipine in patients with acute myocardial infarction: a pooled individual patient data analysis of four randomized, double-blind, controlled, prospective studies. Curr Med Res Opin. 2018; 34 (10):1869-1874. doi:10.1080/03007995.2018.
ORCID and contributionship:

Dmytro V. Martovytskyi - 0000-0003-4005-0267 B,C,D,F

Olexiy M. Shelest - 0000-0002-7283-195X ${ }^{E}$

Pavlo G. Kravchun - 0000-0002-8285-6763 ${ }^{\text {A }}$

\section{Conflict of interest:}

The Authors declare no conflict of interest

\section{CORRESPONDING AUTHOR \\ Dmytro V. Martovitskyi \\ Department of Internal Medicine No. 2, \\ Clinical Immunology and Allergology \\ named after Academician L.T. Malaya, \\ Kharkiv National Medical University, \\ pr. Nauki 4, Kharkov, 58002, Ukraine \\ e-mail:mardima2005@ukr.net}

Received: 28.04.2019

Accepted: 15.11 .2019

A - Work concept and design, B - Data collection and analysis, C - Responsibility for statistical analysis,

D -Writing the article, $\mathbf{E}$-Critical review, $\mathbf{F}$ - Final approval of the article 